\title{
The Ecosystem Approach as a framework for understanding knowledge utilisation
}

$\underline{\text { Roy Haines-Young and Marion Potschin }}$

$$
\begin{aligned}
& \text { Centre for Environmental Management, } \\
& \text { School of Geography, } \\
& \text { University of Nottingham, England NG7 2RD }
\end{aligned}
$$

Roy.Haines-Young@Nottingham.ac.uk 


\title{
The Ecosystem Approach as a framework for understanding knowledge utilisation
}

\begin{abstract}
The Ecosystem Approach is used to analyse four case studies from England to determine what kind of ecosystem knowledge was used by people, and how it shaped their arguments. The results are reported across decisions making venues concerned with: innovation; conflict management; maintenance of ecosystem function; and, recognising the environment as an asset. In each area we identify the sources and uses of conceptual, instrumental, political and social knowledge. We found that the use of these knowledges can benefit the process as well as the quality of outcomes, and so 'add value' to the decision making process. However, the case studies did not exhibit any simple linear-rational model of knowledge use. Ecosystems thinking took many forms and depended on different institutional settings. As an argument making device, the Ecosystem Approach must be seen in the context of a wider set of social and political processes, which involves a range of complex strategies and motives that explain the apparent 'messiness' of environmental decision making. The paper demonstrates that as conceptual framework, the 'ecosystem approach' provides a valuable theoretical template to help us discover how and what knowledge is used in deliberative styles of decision making.
\end{abstract}

Key words: Ecosystem Approach; knowledge utilisation and innovation; environmental decisionmaking; deliberative processes; conflict resolution; ecosystem knowledge.

\section{Introduction}

The Ecosystem Approach has been championed as a way of delivering the conservation of biodiversity and sustainable forms of development ${ }^{1}$. However, although there is a general belief that it can bring a richer body of knowledge into the decision making arena, detailed empirical evidence to substantiate such claims is lacking. To go beyond advocacy we need to identify whether and how the Approach can stimulate the uptake and use of new ecosystem knowledge ${ }^{2}$ (Jordan and Russel, 2013). In what circumstances can it help policy advisors and planners generate new ideas about how to manage and restore ecosystems? To what extent is the Approach effective in overcoming barriers to knowledge exchange and use that have previously frustrated effective environmental management? In this paper we examine the Ecosystem Approach as a framework for knowledge utilisation, rather than as a prescription for practice. Nevertheless conclusions about its effectiveness in supporting evidence-based judgements may shape views about its general significance.

The analysis of knowledge utilisation is complex because it seems to depend on agreeing a priori what constitutes knowledge and the purposes to which it is put. While various typologies for both knowledge types and uses have been suggested (e.g. Rich, 1991; Owens, 2005), these general frameworks only take us so far when looking at what people actually do and how they react. Such typologies may help identify that a particular idea is being used or presented in a strategic rather than an instrumental way, for example, but they do not reveal much about what motivates choices or tactics in particular decision-making situations. As a complement to these more general discussions, we therefore take the proposition of an 'Ecosystem Approach' and use a series of case studies to trace which of its features the various actors deploy. By looking how the principles that constitute the

\footnotetext{
${ }^{1}$ http://www.cbd.int/ecosystem/sourcebook/

2 In this paper we use the term 'ecosystem knowledge' rather than 'environmental knowledge'; although the two can be regarded as synonyms, for us the notion of 'ecosystem knowledge' better capture the idea of ecosystem services and the social-ecological dimension of thinking represented in the Ecosystem Approach, which was being explored in the case studies.
} 
Approach play out in the case studies, we can examine patterns of knowledge utilisation in a range of defined and relevant decision-making venues.

This paper draws on the findings of work in the UK that was sponsored by Central Government ${ }^{3}$. Despite this specific geographical focus, it is relevant to wider international audiences because it focuses on two issues that transcend national concerns, namely how the Ecosystem Approach is applied at local scales, with all the constraints on skills and knowledge that arise at such levels; and, how it can be used to promote the environmental agenda through social and economic means (cf. Mackenzie et al. 2013). For, having subscribed to the principles of the Ecosystem Approach in a number of its policy statements (Defra 2007, 2010; HM Government 2011) there was a desire by UK Government to demonstrate the 'added value' to decision making amongst those which it sought to influence. There was particular interest in showing that it facilitated the exchange and use of what was perceived as new types of ecosystem knowledge between and within the communities of science and policy making. There was also interest in showing that it supported the goals of 'good governance' by promoting adaptive and participatory models of environmental management, and robust evidence-based policy making (Lichens, 2010; Pullin and Knight 2009; Sharpe, 2004; Dunlop, 2013). The authors set out to test these propositions critically, and from an independent perspective examine whether the application of an Ecosystem Approach did indeed lead to the elicitation of different types of knowledge or supported the ideas of good governance.

The EMBED Project, which we discuss here, was therefore set up to investigate of a set of case studies in England; all of them implicitly used some of the core ideas of an Ecosystem Approach to support a decision making process. The purpose in studying them was to identify and measure the value of these ideas compared to what the participants saw as 'traditional' ways of working. Since the results of the EMBED Project have been reported elsewhere we will not focus on the merits of the Ecosystem Approach as such, but reanalyse the body of empirical data that was collected to draw new insights into the processes of knowledge use and exchange that were observed. In relation to the case studies we ask: what kind of ecosystem knowledge is being used by the actors and to what end, and how does ecosystem knowledge shape the argument making strategies that they deploy?

\section{Tracking Knowledge Use: The Methodological Framework}

At the outset of EMBED it was recognised that there are important methodological implications of the case study approach. With a limited number of case studies there was clearly no possibility of making any kind of statistical analyses. Moreover, there was also no prospect of using any external control to help identify how 'ecosystem thinking' shaped decision making relative to some comparator projects that did not use it. To address these methodological difficulties the research strategy selected was a retrospective one; it involved working backward from case study outcomes to the kinds of knowledge that influenced the judgement of decision makers. Overall the methods sought to uncover the factors that influenced thinking, and identify what concepts, ideas or evidence was important in deliberations, together with the sources. Given that all of the actors in the case studies had experience of other projects in other contexts, we also explored whether they could identify any novel or effective elements associated with the framework provided by the Ecosystem Approach.

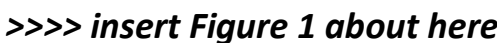

This paper is based on the completed project "Embedding an Ecosystems Approach in Decision Making: Measuring the Added Value", funded by Defra (Project Code: NR0135). 
The overall methodological approach used in the EMBED is summarised in Figure 1. This schema recognises that decision- or policy-making is grounded in a wider socio-ecological context, which includes the ecosystem that is potentially under management. If a decision making process is supported or partly shaped by the ideas that constitute an Ecosystem Approach then we can expect that they must influence the outcomes of policy ultimately how ecosystems are managed and used. The simple model shown in Figure 1 should not, however, be taken to imply that we assume that decision making necessarily follows some kind of linear-rational model, whereby outcomes are completely determined by the application of some prior logic or principles, to an uncontentious body of evidence (cf. Owens, 2005). As the diagram shows, the socio-ecological context needs to be considered, and this includes an understanding of the status and dynamics of the ecosystem under management. This context may provide motivation for, or influence how, an Ecosystem Approach is actually implemented. As the model suggests, contexts may also be changed during the decision making process (dotted arrows) and such feedbacks may redefine how and which principles of the ecosystem approach are applied, and even what kinds of evidence or outcome are legitimate or acceptable. While such 'short-circuiting' may make the decision making process more 'messy', it does not eliminate the possibility of using actual or intended outcomes to uncover what kinds of knowledge they were based on, and what kinds of knowledge exchange processes were involved.

\section{〉>Insert table 1 about here}

The advantage of the methodology adopted for the EMBED Project was that use of externally defined criteria as the basis for investigating the demonstrator projects ensured that the conclusions drawn were not dependent on whether each project met its own, internally-specified, goals and objectives. Instead the material they provided could be used to answer to the more generic question about the value added by the kind of knowledge stimulated by the Ecosystem Approach. Nevertheless, it must be recognised that questions about the 'added value' that the Ecosystem Approach brings to knowledge use are difficult to answer, because whatever it entails it is not applied in a formulaic or linear way. Indeed it was to emphasise the flexible, open character of the concept that Defra reworked the Convention for Biological Diversity (CBD) version into its own statement of them, which it described as an 'Ecosystems Approach'. The plural being used deliberately to emphasise the nonprescriptive character of what was being proposed; that is to highlight the possibility that there might be 'more than one' version of the Approach. Nevertheless, the boundaries of what was being advocated in the UK were clear ${ }^{4}$. Although the twelve original CBD principles were collapsed to just six (Table 1), the importance of holistic, cross-sectoral working, the value of ecosystem services, use within environmental limits, management at appropriate spatial scales, adaptive management strategies, the importance of participatory methods all essential elements of what is 'need to be known'. These themes therefore provided a framework in which the role of a set of specific types of ecosystem knowledge could be investigated.

The four demonstrator projects selected for investigation by EMBED were as follows (see also Appendix 1):

- The Finding Sanctuary Project in SW England (FS), which brought together a number of stakeholders to design a network of Marine Protected Areas (MPAs) off the coast of South West England.

- The Gaywood River Valley Living Landscape Project in Eastern England (aka Gaywood River Valley Surf Project, GVSP), an initiative designed initiative to help realise and value of the

\footnotetext{
${ }^{4}$ For consistency with the wider international literature we retain the singular form in this paper.
} 
natural asset represented by the Gaywood River Valley area for the people of King's Lynn, Norfolk.

- The Natural Economy Northwest Green Infrastructure Project (NENW), which was designed to help 'mainstream' the natural environment within sustainable economic development at the regional Scale in England.

- The Wetland Example of Payment for Ecosystem Services Project (WEPES), which explored the use of market-based mechanisms for water management on the River Fal in West Cornwall.

When selecting the case studies, there was no attempt to be representative of contemporary work in the UK, or to only choose projects that in some way advocated or had 'signed up' to an Ecosystem Approach. Rather, the main considerations were that the projects were already established, that the actors involved were 'willing to be studied', and that the background materials were open to scrutiny. In this respect they simply 'demonstrated' features of current practice. The research goal was to draw on the experience of the demonstrator projects and identify which attributes of an Ecosystem Approach (if any) contributed most to the exploitation of different forms of ecosystem knowledge.

Since many of the ideas contained in the Ecosystem Approach were already considered to be in common use, we anticipated that the demonstrator projects would be using them or may have reflected upon them by default; in any case lack of awareness or the decision that particular topics or concepts were not relevant, would be equally revealing. Moreover, even if the principles of an Ecosystem Approach were not being used the 'real-world' nature of the projects meant that the people involved could reflect on them critically and explore whether they thought that the principles would have change anything already done. However, in terms of the 'position' of each of the demonstrator projects in relation to the ideas of the Ecosystem Approach, it is nevertheless important to note that in gaining support for their work from internal and external sponsors, they may already have had to make arguments that are consistent with such thinking. The Westcountry Rivers Trust website notes, for example, that 'in pursuit of its objectives....the Trust adopted the "Ecosystem Approach" at an early stage of its development..." . Similarly, NENW was partly sponsored by the SITA Trust, a charitable body which is 'an ethical funding organisation dedicated to making lasting improvements to the natural environment and community life ${ }^{\prime 6}$. The North Sea Regional Programme of which the Gaywood Valley Surf project is part, aims at 'enhancing the overall quality of life ....by ensuring that there is access to more and better jobs, by sustaining and enhancing the acknowledged environmental qualities of the region" ${ }^{7}$.

EMBED was designed as a longitudinal study so that we could observe how work within each of the demonstrator projects evolved over time. Our study began in 2009 and was completed in 2011, and so reflects the thinking at or around the time when UK Government was formulating its Action Plan and subsequent initiatives (Defra, $2007 \&$ 2010). The evidence was collected through direct observation and from inspection of relevant documentary sources, or gathered through questionnaires. A particularly important source was interviews with Key Informants (KIs), who were largely responsible for the leading projects (in some cases there were several KIs), and their Stakeholders (SH); the latter included decision- and policy- makers and other users of information and outcomes delivered by the respective projects. We have also, where possible, collected information from stakeholders relating to the value of the approaches used in the demonstrator projects, the outcomes achieved and the added-value to each stakeholder group that these outcomes represented. Five stakeholders were interviewed in each of the case studies, except for WEPES

\footnotetext{
${ }^{5}$ http://www.theriverstrust.org/environment/ecosystem/eco approach.htm

${ }^{6}$ http://www.sitatrust.org.uk/about-us

7 http://www.northsearegion.eu/ivb/content/show/\&tid=75
} 
project, where there were sensitivity issues; here only the views of the $\mathrm{KI}$ are reported. All interviews were recorded and the transcribed material re-presented for approval to participants in the form of a summary document organised around the different knowledge components of the Ecosystem Approach.

\section{Utilising Ecosystem Knowledge}

While none of the demonstrator projects overtly used an Ecosystem Approach, we found that many of its key features and practices were being applied in some way, or that the experience and background of the participants enabled them to take a critical view about aspects of its application. As a result, the evidence collected gives some empirically grounded insights into the effectiveness of the principles as 'argument making' and 'problem solving' mechanisms. 'Ecosystems thinking' appeared to have an impact on the process as well as on the quality or character of project outcomes, and appeared to involve the use of different types of ecosystem knowledge for a range of different purposes.

To describe these types of knowledge use we use a typology based on the three main categories suggested by Hertin et al. (2009; see also McKenzie et al., 2013), namely 'conceptual', 'instrumental' and 'political', to which we add a fourth 'social'. While we take conceptual knowledge to cover general ideas that enlighten and stimulate new perspectives at the individual level, we use the term 'instrumental knowledge' to cover the 'harder' kinds of evidence which are often accepted as facts or how things are. We use the term 'political knowledge' to describe understandings of the positions taken by different groups, represented by the arguments they make and which can be made against them. Finally, we use the new term 'social knowledge' to identify common understandings that arise as a result of group or participatory processes; this is the stuff of social learning (cf. Reed et al. 2010). Although collaborative working can transform perceptions at the individual level, there is another aspect of group learning that is distinct and influential: people can develop shared understandings about how to work together. Social knowledge involves, for example, understanding what the 'rules of engagement' are, not so much to achieve particular political outcomes, but to develop something like shared ownership of a problem, issue or task. Looked at in another way, social knowledge is what turns 'useful' information into 'usable' information (cf. Lemons et al. 2012) in collaborative, multipartner projects of the kind studied here.

Although the typology presented above provides a useful set of descriptors, it was not able to fully capture how knowledge was used 'on the ground'. Our experience suggested, for example, that an idea or concept could be used in different ways at different types by different actors, and it could not be labelled immutably 'conceptual' or 'instrumental' etc. Instead, to unpick the complexities of what was observed, a more workable approach involved identifying four of the major themes embodied in the Ecosystem Approach describe the knowledge 'games' that were being played out in these different decision-making venues. The four areas selected cover innovation, conflict resolution, maintaining ecosystem integrity and the representation of the environment as an asset.

\subsection{Encouraging innovation}

One way that an Ecosystem Approach might add value is by encouraging new and innovative ways of problem solving, especially at the group (i.e. social level). Such innovations may include transforming perspectives so that people take a more holistic or cross-sectoral view of issues, or be motivated to include a wider range of stakeholder perspectives in debates. We investigated this proposition with each of the demonstrator projects both separately and as a group in a cross-comparison workshop involving all partners at the end of the EMBED project. All provided evidence to suggest that 
conceptual ecosystem knowledge in some form was used to enable or attempt such transformations in thinking.

When exploring questions of 'novelty' it is important to note that what is new to some might not be seen as innovative by others. This is particularly so in the case of projects which aim to be crosssectoral; by reaching out to a range of groups to influence their behaviour, it is inevitable that some might look at the kinds of thinking embodied in an Ecosystem Approach as if for the first time. While all demonstrator projects provided examples of how ecosystem knowledge was actively used at a conceptual level, it was particularly marked in the case of Natural Economy North West (NENW).

The self-understanding within the NENW management team at the end of the project in 2009/10 was that it was primarily about identifying and valuing the benefits of Green Infrastructure (GI) in multifunctional terms. They argued that this was equivalent to taking an 'Ecosystem Services Approach', with the latter seen as equivalent to an Ecosystem Approach (cf. Potschin and HainesYoung, 2011). The blending of terminology clearly suggests that the ecosystem service concept was at the core of what they do, however, the link they made with the concept of Green Infrastructure (GI) was more revealing. The focus on GI was justified because it was seen by the interviewees as a way of expressing the core ideas of an Ecosystem Approach in 'language that those which NENW sought to influence would understand', given their professional background. Others subsequently involved with taking the legacy of NENW forward argued that in retrospect the history of the project was 'more complex'.

Looking back in 2011, the Key Informant (KI) that had taken over leadership of NENW Project suggested that when it was first initiated, GI was, in fact, not one of its central concerns, and that part of the early discussions involved making a case for including it; this view was confirmed by other stakeholder interviews. The focus of NENW was to deliver a set of priority actions under the then Regional Economic Strategy, which involved optimising the contribution of the natural environment to the regional economy and quality of life. The understanding of our KI was that 'Green Infrastructure' was an idea 'imported from the US' as a way to make more effective arguments in favour of the environment; it was used 'precisely for this end'. He observed that within the project, interest in Gl pre-dated the attention that the concept of ecosystem services, but that as the project progressed a closer alignment between the two sets of ideas developed, with Green Infrastructure being seen the means by which ecosystem services could be delivered.

Whether or not we regard NENW as based on the principles of an Ecosystem Approach from the outset, the evidence collected suggested that it was eventually seen as embodying many of them, especially that involving environmental values. It is also apparent that the situation developed through a process of iterative learning within the project team and amongst its partners, resonant with the 'short-circuiting' suggested in Figure 1. While the wider social and ecological benefits of Green Infrastructure were acknowledged by NENW, there was an explicit attempt to make monetary estimates of the value of investments in $\mathrm{Gl}$ as part of the argument making and influence spreading process. A point emphasised by all interviewees associated with NENW was that the project operated in a context where additional finance for 'green investment' had to be won. Any such investment had to be justified and described in languages relevant to these wider constituencies. Our KI felt that the concept of Gl enabled them to enrol the 'hard to reach' stakeholders (such as planners) because it was consistent with their goals of securing economic and social benefits; the strategy was not an obvious one at the start but developed as the concept of GI was explored and applied, and different arguments tried. 
While NEWN clearly demonstrated the importance of conceptual ecosystem knowledge as a way of transforming perspectives, the work is also of interest because it illustrated how, over time, as conceptual knowledge was assimilated, novel instrumental forms of knowledge also emerged. Thus the experience gained through NENW and other associated work in NW England has given rise to new tools for mapping the functions and benefits of $\mathrm{Gl}$, and of calculating the economic benefits that investment in $\mathrm{GI}$ might make ${ }^{8}$. It has also stimulated initiatives concerned with modelling the impact of changes in $\mathrm{Gl}$ on temperature and runoff, as part of climate change mitigation ${ }^{9}$.

Conceptual innovation stimulated by new forms of ecosystem knowledge was also identified by participants in the other demonstrator projects as adding value to the work they were doing. The Key Informant from the Gaywood Valley Surf Project, for example, agreed that ecosystems thinking had provided a 'creative problem reframing' device that stimulated the design of 'novel solutions'. This project was led by the Borough Council of King's Lynn and West Norfolk, where a local councillor saw it as an innovative and potentially fruitful way of taking forward the Council's multiple objectives for the area; these were already expressed in, for example, Local Development Framework and growth strategy for the town. However, the project showed that the power of ecosystem knowledge was not merely operating at a conceptual level. Our key informant went on to describe some more 'political' uses of ecosystem knowledge. They felt that part of the process of achieving 'local buy-in' was the identification of a 'unique selling point' for the project. Arguments along the lines of people having done this kind of thing elsewhere only went so far, it was suggested; stakeholders also sometimes want to feel that they are breaking new ground. The link between the Gaywood Project and the larger EU-funded SURF Project was seen as a particularly important in this regard, by signalling the international significance of the issues and the potential contribution to wider thinking that the local work might make, the political case for the work had been strengthened.

\subsection{Conflict management}

The use of ecosystem knowledge to help resolve conflicts between different interest groups could be seen as a second way in which an ecosystem approach might 'add value'. As might be expected, our study showed that the outcomes of all the demonstrator projects depended on building consensus and trust between different interest groups. More interestingly, however, it was apparent that this outcome was achieved in different situations through different types of ecosystem knowledge; conflict management is not simply a matter of addressing political issues. Disputes could arise not just out of groups having different conceptual or political perspectives, but also at a more instrumental level involving different ideas about what constituted 'appropriate' or 'legitimate' evidence (cf. Dunlop, 2013; Waylen, 2013). The four projects also demonstrated how, to different degrees, the management of conflicts was dependent on the development of different forms of 'social knowledge'.

The management of different interest groups was a particular feature of the Finding Sanctuary Project. Given that the main task was to achieve an agreed set of recommendations for the design of a set of Marine Protection Areas (MPAs), key issues were whether all interests were represented in discussions, and ultimately whether some kind of consensus could be achieved about where the threats and opportunities were for conserving biodiversity. Our Key Informant observed that there had been noticeable shifts in understandings between stakeholders during the work. They suggested that the motivations for the involvement of each stakeholder group were different; some were 'paid' in the sense that they represent recognised organisations or constituencies (such as the fishing

\footnotetext{
${ }^{8}$ http://www.greeninfrastructurenw.co.uk/html/index.php?page=projects\&GreenInfrastructureValuationToolkit=true

${ }^{9}$ http://www.greeninfrastructurenw.co.uk/resources/framework for web.pdf
} 
industry) while others participated on a voluntary basis. While recruitment was not based on any formal stakeholder analysis, there was an attempt to make the process inclusive and transparent through advertising. Setting questions of balanced representation aside, it was also apparent that the process of knowledge creation and exchange developed during the work allowed this diverse group of around forty individuals to see the 'expert in themselves'.

A significant feature of the FS Project was the way it created new conceptual and instrumental ecosystem knowledge by working with the different stakeholder groups to identify how and where they used the marine space, and where conflicts between different uses and conservation goals might arise. Our KI argued that the creation of mapping tools and an associated database had empowered people to analyse data and make decisions in ways 'they would not have expected'. For example, it was reported that while initially the stakeholders were reluctant to 'draw lines on maps', over the course of the project they showed increasing confidence to do so. Working groups used 'building blocks' that drew on the data assembled by FS team, together with guidance documents that specified targets in relating to different marine habitats; the groups met 20-25 times over the period of the project and agreed proposals for the design of the network. Our KI observed that many changes to initial ideas were made, more than 'in other types of project were stakeholders were not so actively involved'.

Significant instrumental knowledge creation that took place within FS; about half of the project resources were invested in the development of the underlying data resources and the rest on management and facilitating the deliberative process and reporting. However, the focus on data generation should not obscure the fact that a good deal of social learning occurred that enabled this potentially usable information to be turned into useful conceptual and instrumental knowledge. For example, our KI stressed that as a result of the deliberations the stakeholders learned to accept that they had to deal with uncertainty 'and develop assumptions that enable them to work with that'. Moreover, it is also apparent that considerable social knowledge was developed within the group. Our KI noted that all stakeholders had to compromise, and potentially work with the 'asymmetry of the process'. In terms of the conflicts between conservation and use of the marine space, commercial interests 'could only lose given the terms of reference for FS', while 'anything set aside or protected represents a gain for the conservation lobby'. A further interesting political driver was the knowledge that unless there was some agreement between stakeholders, the design of the MPAs would be imposed by the Joint Nature Conservation Committee under the terms of the Marine Bill. Thus the stakeholders saw it as in their best interest to collaborate.

The creation of a reliable, credible and accepted 'evidence-base' (i.e. a body of instrumental knowledge) was that in some way facilitated stakeholder trust and engagement was also evidence in the WEPES demonstrator project. The KI for this study stressed his role as a knowledge broker or intermediary, bringing both 'scientific knowledge' to the table, and understanding the positions of the main players: land owners and South West Water. The small size of the WEPES project meant that extensive stakeholder elicitation was not possible. However, the KI was able to describe similar situations in other areas, where the effectiveness of the tools and techniques used in WEPES were could be demonstrated. Once again mapping was found provide a convincing evidence base for establishing Payment for Ecosystem Service (PES) schemes. The KI argued that to establish confidence between the buyers and sellers, there needs to be a credible body of general evidence about the effectiveness of particular sorts of interventions'. From his perspective, this provided the basis for a strategic plan for the catchments being targeted that made a 'believable case' for where interventions would be most effective. He described how GIS had been used to identify 'Zones of 
Potential Agreement' for action or intervention, and how these results were used as a framework for discussions and for achieving consensus amongst stakeholders. As in Finding Sanctuary, it enabled stakeholders in WEPES to work with uncertain knowledge in a 'pragmatic' way. The KI explained that mapping was created with stakeholder involvement and could be used to establish 'best-estimates' for the costs and benefits of providing ecosystem services.

The success of the deliberative or sequential bargaining processes undertaken in WEPES and similar initiatives led by the West Country Rivers Trust was felt to be partly due to the experience and independent standing of the organisation. It was argued that this brought 'credibility to the process'. Some form of knowledge brokerage was also identified as significant in the other three projects, which all agreed with our summary conclusion that there 'appeared to be a need within all of them to have access to trusted advice, expertise and facilitation skills, to interpret and respond to stakeholder needs'. They also agreed that expertise should 'support a client-focused process rather than dictate what needs to or can be done', and that experts, like stakeholders should also 'learn'. Knowledge brokerage therefore clearly involves the creation of social knowledge as well as the interpretation of external sources of conceptual or instrumental knowledge for local contexts. The space that the ecosystem approach creates for such brokerage roles could be seen as another way in which it adds value to decision making and consensus building processes.

\subsection{Maintaining ecosystem function}

A third way in which an ecosystem approach might be said to 'add value' to decision making is if it results in better ecological outcomes. According to the principles of an Ecosystem Approach this requires, for example, that environmental limits are understood and respected.

The influence of an Ecosystem Approach on the long term status of ecosystem services as the result of demonstrator projects is impossible to judge, because time scale over which EMBED has tracked them is too short. Nevertheless, it was clear from the material collected that people felt that the current and future status of the environment was likely to be more secure as a result of their work. Paradoxically, however, knowledge about 'ecosystem integrity' or 'ecosystem health' were not found to figure strongly in the debates surrounding most of the demonstrator projects, nor did the projects focus too much on what constituted successful outcomes in terms of ecosystem functioning or the output of ecosystem services. Only in Finding Sanctuary and WEPES did traditional conservation objectives seem to significantly shape the agenda, but in these cases it was not clear how they would be realised as a result of the projects; in both cases the key factor was an agreement that the environmental trajectory would be positive rather that specific targets would be achieved.

For example, while the policy setting of Finding Sanctuary clearly meant that it was about managing the impacts of activities in the marine space, our $\mathrm{KI}$ suggested that discussion of what the project would deliver in conservation terms was not part of the process. It was suggested that since there were so many potential drivers of change, any expectation that the MPA network would address them may have introduced too much complexity into the consultation process. He added that in reality the Project tended to steer people away from specifying expectations - because change is slow and uncertain; 'what is expected to happen has never really figured into the decision making process'. The conservation objectives for the sites were only to be written after they had been identified and there would be no chance to go back to revise the network; only concerns could be noted. The interviewee identified that the danger here was that the whole deliberative process could be undermined and even manipulated if conservation objectives turned out to be more restrictive than was assumed during the consultative process; and example of how knowledge that at one time 
could be viewed as instrumental, since it supported an analytical process, can be transformed into political knowledge in other contexts or venues.

In terms of the kinds of ecosystem knowledge used in the debates it is interesting to note that while the concepts of ecological thresholds and limits figure strongly in the principles of an Ecosystem Approach, the evidence collected from the demonstrator projects suggested that they were not important issues that shaped the work, and were indeed avoided. In some of the demonstrator projects 'limits thinking' was, in fact, seen as 'too negative' and other argument making strategies that stressed opportunities and benefits were thought of as being more useful.

In the case of Finding Sanctuary, the KI suggested that it would also have been 'counter-productive' to introduce limits thinking into the discussion because this would possibly have led to more entrenched political positions. What was interesting here, however, was that notions of environmental limits did permeate and shape discussions albeit in a less explicit way. It was suggested by the $\mathrm{KI}$ that the nationally specified minimum requirements and guidelines set for the design an MPA network did much to facilitate the process. The guidelines set minimum size and maximum spacing requirements for the Marine Conservation Zones (MCZs). It was understood that the recommendations for the MCZ boundaries generated through Finding Sanctuary had to comply with these national-level guidelines or risk being overturned and replaced by externally imposed boundaries that might not take account of local and regional socio-economic interests.

The $\mathrm{KI}$ observed that at the start of the project the national guidelines were not available; this is confirmed in the published advice to Government on the outcomes of the initiative (see JNCC and Natural England, 2012 p.92). The document noted that the 'stakeholders identified the need to understand the "full picture" of what they were being asked to do before proceeding with the process to identify sites. For example, they cited that the final version of ENG [Ecological Network Guidance] was not published until June 2010 and the PDG [Project Delivery Guidance], up to six months after their first meeting'. While the document goes on to question the impact of these delays on the outcome, the KI confirmed that once they were available they did much to structure the process. The development of this 'social knowledge' was clearly an essential part of building an understanding of how the deliberative process would work, and what the constraints on decision making were. Our KI observed that it was often difficult to defend these constraints 'scientifically' and they are often contested by the commercial interests. Ultimately, he felt, they had to be decided through 'an almost political process' because it was recognised that 'agreement was needed'. Understanding the political limits of the deliberative process was therefore an important part of the knowledge created through Finding Sanctuary.

In the case of NENW 'limits thinking' was also found to have little value. Here the KI stressed that the challenge was to 'sell GI in terms of benefits', because 'our audience did not want to know about limits'. He went on to suggest that where problems needed to be identified it was better to talk in terms of 'needs' rather than limits. Similar perspectives on limits thinking emerged from the WEPES and GVSP demonstrators. The use of mapping techniques to identify 'Zones of Potential Agreement' in WEPES was noted above. In the GVSP, our KI reported that the knowledge about environmental limits was relevant initially as a result of an early consultants' report which highlighted the fact that there was limited development land available that was not subject to a high level of flood risk. Our KI observed that because the flood issue can be a very sensitive one for communities, more progress could be made by instead, making the case for nature. They felt that because countryside and wildlife are important assets for the region they could work with the idea that the Valley represented one of the 'biggest strategic areas of accessible green space'. The interview with our KI and a Local Councillor 
involved with the project confirmed that the aim of the project was to deliver social and economic benefits through the environment, and so improve the well-being of people. The Councillor stressed that King's Lynn included areas of significant social deprivation; for him there was a need to make the area more attractive to inward investment, and to stimulate behaviour change, in terms of the way people frequent open space, so as to achieve significant health benefits. Our KI felt, however, that evidence base for the benefits of the environment was difficult to construct, and this was an important knowledge gap.

While we might expect the need to maintain ecosystem function to be one area which would show the strongest use of conceptual and instrumental knowledge, the evidence collected suggests that particular conceptual or instrumental issues or ideas can be avoided if they have the potential to frustrate or complicate social or political processes. The idea of maintaining ecosystem function acted more as a kind of bounding principle, and that while people bought into the goal of improving environmental outcomes, they were less concerned about specifying what exactly these might be. Alongside ideas about environmental thresholds, concepts such as ecosystem integrity or ecosystem health did not often figure strongly in the debates we followed. Indeed at least two of the projects (NENW and GVSP), were clearly dealing more with socio-ecological systems than ecosystems, and were more concerned to deliver social and economic benefits through the environment rather than to achieve ecosystem integrity per se. Thus there was more of a need to understand better how these socio-ecological systems worked, not just the biophysical components of it. In this respect, principles of an Ecosystem Approach did not fully define the kinds of conceptual and instrumental knowledge that people required in the case studies.

\subsection{Recognising the environment as an asset}

Of all the themes covered by the Ecosystem Approach, the need to recognise the value of the environment stood out as one of the major areas of concern in all the demonstrator projects. Indeed in general terms, it was probably one of the most active areas of knowledge creation undertaken within each of the initiatives. The notion of the environment as an asset was common place amongst those interviewed, and the need to find evidence to support the claim that it provided important flows of benefits to people was a frequent concern. Statements about value were generally seen as ways of identifying the positive aspects of the initiatives, in contrast to understandings of environmental limits and thresholds, for example (see 3.2, above). It was apparent, however, that while knowledge of economic values could be important for eliciting support, debates often turned on much wider understandings of value than were captured in monetary estimates. Indeed in some cases explicit valuation in economic terms was avoided if it was considered counter-productive.

The two demonstrator projects in which economic estimates of the value of the natural environment were used in a more central way were Natural Economy North West, and WEPES. In former economic valuation was seen as a pre-requisite to making arguments about the need to invest in Green Infrastructure in development projects. In the latter, estimates of the economic value of improving water quality were used to justify the costs of paying land managers to act in 'beneficial ways' in the long term. In both cases, however, while such knowledge was used, the case studies demonstrated that monetary estimates were only part of a much wider framing of the significance of the environment as an asset. In fact, attempts to provide economic estimates of the value for Green Infrastructure did not arise until the later stages of the project, with earlier work focussing more on the qualitative relations between $\mathrm{Gl}$ and the social objectives set out in the Region Strategy (Appendix 1). Our Key Informant for NENW suggested that in many ways the qualitative work on 
value was perhaps more useful because the methods used to derive monetary estimates were regarded as contentious by some partners.

In contrast to Natural Economy North West and WEPES, there was evidence from the other two demonstrators that in some circumstances questions of value did not always boil down to questions of economic value, and indeed a focus on economics may have detracted from intended outcomes. This was most apparent in Finding Sanctuary, for example, where the discussion was deliberately framed around what kinds of activity should be permitted in each potential protected area, rather than in terms of the economic impact of any particular MPA design option. It was recognised that economic valuation of the impact would only occur after proposals were made, as part of the final an impact assessment at national level. However, the KI felt that 'this kind of analysis would have complicated things too much early on', and stressed the work had been undertaken before the formal consultation with the aim of 'speeding things up at the enquiry stage', by gaining prior agreement amongst stakeholders.

The Gaywood Valley Surf Project also provided an illustration of the need to develop a set of shared social values through the creation of knowledge about the environment as an 'asset'. Our KI for this described the situation at the start of their work as being one characterised by limited public awareness, even of the Gaywood Valley itself. People used the area and generally regarded it as simply part of the urban fringe. The Valley had no identity as 'place' with its own particular characteristics or opportunities; as a result it was difficult to enrol people in the initiative. One of the tasks for the project had therefore been that of 'place-making' (cf. Potschin and Haines-Young, 2013). The assumption is that better place recognition will lead to both better public engagement and better public use of the environmental resource; in terms of the model shown in Figure 1, this amounts to changing the context under which environmental management or intervention is attempted, and illustrates the iterative, rather than linear, character of such work.

In the Gaywood Valley Surf Project, place-making had involved helping people identify and appreciate the qualities of their locality, and turn what was regarded as an unexceptional landscape into one that mattered to people. The Project therefore included a number of 'educational initiatives' designed to increase public awareness and understanding of the opportunities and resources that the area provided; ecosystem knowledge was, in other words, deliberately used to shape the values people held about their surroundings. This shared social knowledge was generated by encouraging the development of new conceptual and instrumental knowledges in the public arena. For example, a school competition for the design of a project logo was found to be effective in awareness-raising and promoting inclusion, as was a wider 'love it - hate it' survey amongst local residents, designed to elicit local people's feelings about Gaywood Valley. The involvement of a local University also enabled a 'fly through' to be made available on the internet. As a measure of the success of these efforts at place-making, the KI pointed to the fact that the name 'Gaywood Valley' was starting to be used in the local media in a way it had not prior to the Project.

\section{Understanding knowledge utilisation: what the studies can tell us}

What kind of ecosystem knowledge was being used by the actors in our case studies and to what end? How did ecosystem knowledge shape the argument making strategies that they deployed? While it is impossible to generalise from a set of only four examples, the observations that we have made can help us to see the subtleties of the processes and the theoretical complexities that must eventually be addressed. Three lessons emerge from the work presented here.

First, that none of the demonstrator projects conformed to anything like a rational-linear model of decision making (cf. Owens, 2005). Instead the work appeared to be more iterative in character 
involving a good deal of co-production of new knowledge. As new knowledge was generated by the projects, the contexts in which the projects operated changed, and as the terms of debate evolved old knowledge could be looked at in new ways and other perspectives could be explored and compared with what was originally intended; an example of the 'added value' that adopting an ecosystem approach might generate. While examples of 'messy' processes of knowledge use and decision making are hardly original, the novel insight that the case studies seem to provide is that this 'messiness' is a necessary feature of the decision making process itself, a process dependent on the combination and evolution of different types of knowledge from different sources. A feature evident from all of the projects was that conceptual types of knowledge seemed to mainly originate from external sources, whereas more instrumental forms of knowledge tended to be generated within the projects. Thus while new concepts and ideas may have needed explaining and refining in the local context, the creation of an 'agreed evidence base' containing instrumental types of knowledge was often the way in which acceptance, trust and ultimately agreement was achieved. For such instrumental knowledge to be accepted as the 'basis for discussion', the case studies showed that a good deal of social learning had to take place to create the trust and understanding needed to exploit these data- and such social learning is fundamentally iterative, because people need to consider, weigh and gain experience in using new ideas. Our case studies suggest that some of the messiness in decision-making may be better understood if we see that it involves both knowledge use and knowledge generation and that the balance between these activities can change within a project, as external influences are refined and applied to local or particular situations. The users and produces of knowledge are often one and the same (cf Lemos et al., 2012).

A second insight to emerge from the demonstrator projects is while the recognition conceptual, instrumental, social and political types of knowledge are helpful in discussion there is probably no sense in which a parcel of knowledge can be assigned to one or other of these categories. Again part of the messiness of decision making can be explained by the fact that an idea or data item can be used simultaneously for conceptual, instrumental social or political purposes, and so the analysis of context in which use is occurring is essential. We need to understand the ends to which knowledge is being put before we can label it. For example, in the case of NENW the generation of instrumental knowledge in the form of economic valuation data was seen as a pre-requisite to making political arguments about the need to invest in Green Infrastructure. Similarly in WEPES, estimates of the economic value of improving water quality were used to justify the costs of paying land managers to act in 'beneficial ways' in the long term. Here it was apparent that while the design of Payment Schemes for Ecosystem Services required the availability of conceptual and instrumental knowledge, ultimately outcomes involved a bargaining process that also depended on the creation of social knowledge, in the form of trust, shared understandings and a common vision for a catchment.

The third lesson that seems to emerge from the case studies concerns the problem of explaining what certain kinds of knowledge are not used or have 'little effect' in particular decision making situations (Weiss, 1979). The observation that there seem to be gaps in the evidence base that people use might also contribute to the perception that decision-making is messy. However, recognition that some of these omissions are deliberate and strategic may help clarify what is going on. Decision making in the four case studies presented here is not an academic exercise in which all forms of knowledge have to be considered and tested, but a set of actions undertaken in a social and political context. The objective is to win the argument or persuade, not to gain perfect knowledge of the socio-ecological system that is to be managed. If, for example, arguments about environmental limits or economic consequences are likely to complicate matters then they will not be deployed. The case studies suggest that future theories of knowledge use must also explain why on occasion 
knowledge is also disregarded. The contribution of these case studies is that they demonstrate quite clearly that Ecosystem Approach is not a set of principles that can be applied regardless of any reaction to the ideas; in exploring its use and understanding its application, we must always be sensitive to social context as well as content (cf. Cowell and Lennon, 2013).

The methodological challenge that we face as researchers concerned with understanding knowledge utilisation is to find ways of exploring unique decision making situations and learning from them. The examples reported here do seem to demonstrate that for the people participating in the projects, thinking in terms of an Ecosystem Approach had some 'added value'; it stimulated the creation of new knowledge and facilitated deliberative styles of decision making. In addition to the particular observations that we have made in our set of case studies, this work has shown that as an analytical template the Ecosystem Approach has much to offer. Whether its principles are sufficient to make it an efficient or effective governance mechanism, this paper has shown that methodologically the Ecosystem Approach provides a framework against which the actions and motives of individuals and groups can be observed to better identify the strategies and tactics they use. The practical lessons that will emerge from such work may help us to embed the use of ecosystem knowledge more firmly in wider decision-making processes (cf Turnpenny and Russel, 2013; Jordan and Russel, 2013). Our case studies show that as an argument making device, the Ecosystem Approach must be seen in the context of a wider set of social and political processes, which involves a range of complex strategies and motives that explain the apparent 'messiness' of environmental decision making.

\section{Acknowledgements}

We acknowledge the support of Defra (Project Number NR0135) and input of Paul Weaver (Groundswell Research) and Rob Fish (Ormi Consulting) who worked as consultants on the earlier part of EMBED. Most of all we acknowledge the many people who have kindly given their time and helped us assemble the evidence base needed for this study. We also thank them for the ideas and insights that they have given us; their experience is an invaluable asset. We also thank the anonymous referees for their helpful comments.

\section{References}

Cowell, R. and Lennon, M. (2013) The utilization of environmental knowledge in land use planning: drawing lessons for an ecosystem services approach. Environment and Planning $C$

Defra (2007) Securing a healthy natural environment: an action plan for embedding the ecosystem approach. Department for Environment, Food and Rural Affairs.

Defra (2010) Delivering a healthy natural environment: An update to "Securing a healthy natural environment: An action plan for embedding an Ecosystems Approach".

Dunlop, C. (2013) Achieving Equilibrium in Evidence-Based Policymaking: Managing Epistemic Supply and Demand in Ecosystems Services. Environment and Planning $C$

HM Government (2011) The Natural Choice: Securing the Value of Nature. CM 8082.

Hertin, J., Turnpenny, J., Jordan, A., Nilsson, M., Russel, D., and Nykvist, B., (2009) Rationalising the policy mess? Ex ante assessment and the utilisation of knowledge in the policy process. Environment and Planning A , 41, 1185-1200.

JNCC and Natural England (2012) Marine Conservation Zone Project. JNCC and Natural England advice to Defra on recommended Marine Conservation Zones. Peterborough and Sheffield.

Jordan, A. and Russel, D. (2013) Embedding an Ecosystems Approach? The Utilisation of Ecological Knowledges in Decision Making. Environment and Planning C 
Lemons, M.C., Kirchoff , C.J. and Ramprasad, V. (2012) Narrowing the climate information usability gap. Nature Climate Change, 1614(2), 789-794.

Likens, G. E. (2010) The role of science in decision making: Does evidence-based science drive environmental policy? Frontiers in Ecology and the Environment 8(6), e1-e9.

McKenzie, E., Posner, S., Tillmann, P., Bernhardt, J.R., Howard, K., and Rosenthal, A. (2013) Use of ecosystem service knowledge in decision-making - How, when, why and by whom? Lessons from three international cases of spatial planning. Environment and Planning $\mathrm{C}$.

Owens, S. (2005) Making a difference? Some perspectives on environmental research and policy. Transactions of the Institute of British Geographers NS 30, 287-292.

Potschin, M., Haines-Young, R. and R. Fish (2011): Embedding an Ecosystems Approach in Decision Making: Measuring the Added Value. Full Technical Report. Defra Project Code: NR0135. Download at: http://www.nottingham.ac.uk/CEM/research.htm

Potschin, M. and Haines-Young, R. (2013) Landscape sustainability and the place-based analysis of ecosystem services. Landscape Ecology (available online), 10.1007/s10980-012-9756-x.

Pullin, A. S. and T. M. Knight (2009) Doing more good than harm - Building an evidence-base for conservation and environmental management. Biological Conservation, 142(5), 931-934.

Reed, M. S., Evely, A.C., Cundill, G., Fazey, I., Glass, J., Laing A, Newig, J. , Parrish B., Prell, C. , Raymond, C., and Stringer, L.C. (2010) What is social learning? Ecology and Society 15(4): r1. [online] URL: http://www.ecologyandsociety.org/vol15/iss4/resp1/

Rich, R. F. (1991) Knowledge Creation, Diffusion and Utilization: Perspectives of the Founding Editor of Knowledge. Science Communication, 12(3), 319-337.

Sharpe, M. (2004) Weighing the evidence: Prospects for evidence-based policy-making. Journal of Environmental Monitoring 6(10), 114N-117N.

Turnpenny, J. and Russel, D. (2013) The challenge of embedding an ecosystem services approach: patterns of knowledge utilisation in public policy appraisal. Environment and Planning $C$

Weaver, P., Potschin, M. and R. Haines-Young (2010) Embedding an Ecosystems Approach in Decision Making; Measuring the Added Value. WP1 Methodology. Defra Project Code: NR0135.

Waylen, K. (2013) Expectations and experiences of diverse forms of knowledge use: the case of the UK National Ecosystem Assessment. Environment and Planning C

Weiss, C. (1979) The Many Meanings of Research Utilization. Public Administration Review 39(5), 426431 
Figure 1: A decision making system supported by an Ecosystems Approach (modified from Weaver et al., 2010)

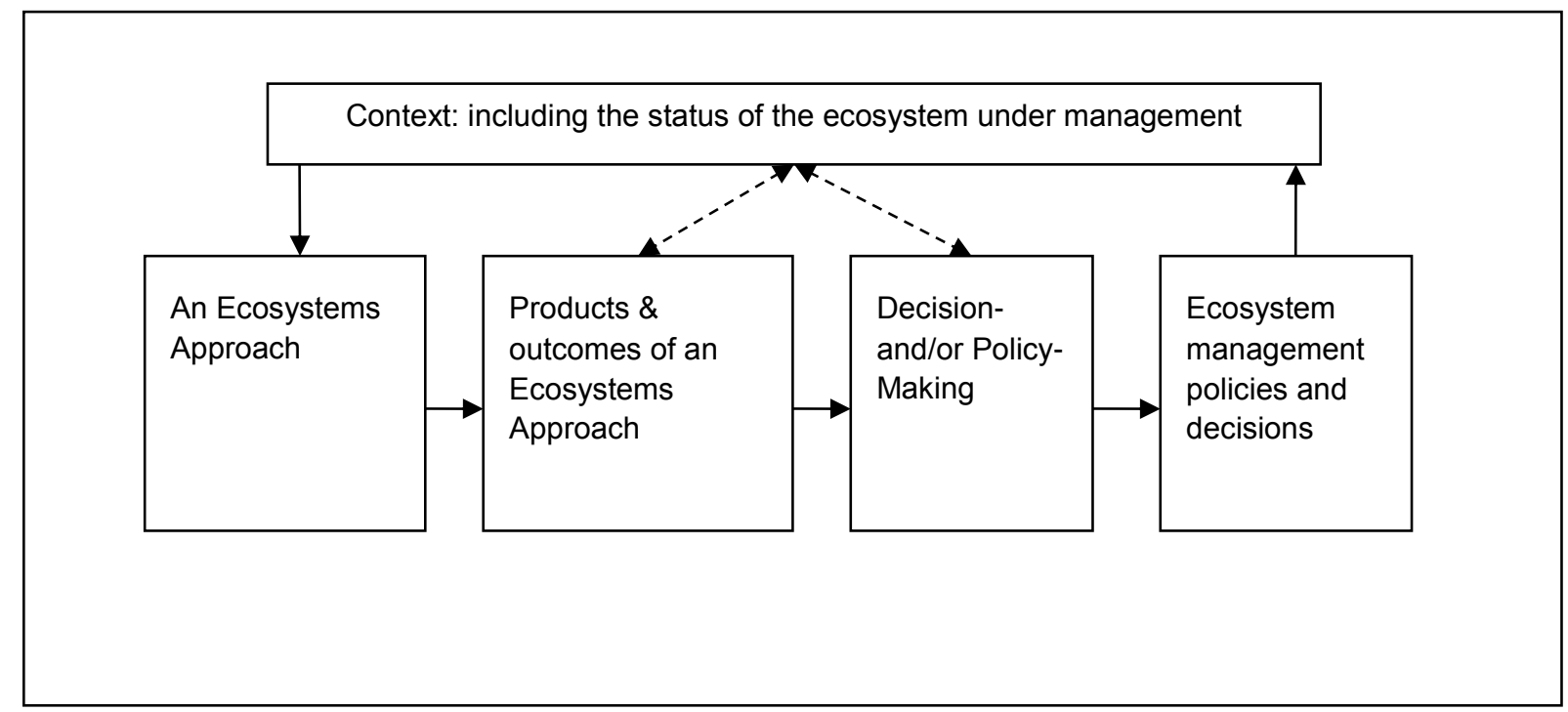




\section{Table 1: The Principles Underpinning an Ecosystems Approach (Defra, 2010)}

1. Taking a more holistic approach to policy-making and delivery, with the focus on maintaining healthy ecosystems and ecosystem services;

2. Ensuring that the value of ecosystem services are fully reflected in decision-making;

3. Ensuring that environmental limits are respected in the context of sustainable development, taking into account ecosystem functioning;

4. Taking decisions at the appropriate spatial scale, while recognising the cumulative impacts of decisions;

5. Promoting adaptive management of the natural environment to respond to changing pressures, including climate change; and,

6. Identifying and involving all relevant stakeholders in the decision and plan making process. 


\section{Appendix 1: Details of the EMBED Demonstrator Projects}

When planning the study around 20 projects were considered for investigation, from which four (Table A1) were selected:

- The Finding Sanctuary Project in SW England (FS): this was a partnership project which brought together a number of stakeholders to design a network of Marine Protected Areas (MPAs) off the coast of South West England. It was one of four regional initiatives to be set up around the English coast under the umbrella Marine Conservation Zone Project established by Defra, Natural England and the Joint Nature Conservation Committee (JNCC). All were tasked with making recommendations for an MPA networks to achieve the objectives for marine nature conservation set out in the 2009 Marine and Coastal Access Act. FS was selected for EMBED to enable marine issues surrounding an Ecosystems Approach to be explored, and because it was the most advanced of the four national MPA studies. FS began in 2009 and is now completed in that the recommendations for the proposed network of MPAs are with JNCC and Natural England who use the information to give formal advice to Government.

- The Gaywood River Valley Living Landscape Project in Eastern England, which is part of the EUfunded SURF Project, abbreviated here as the Gaywood Valley Surf Project, (GVSP): the aims of this initiative have been to assess the role and help realise and value of the natural asset represented by the Gaywood River Valley area for the people of King's Lynn, Norfolk. The goal has been to develop a holistic approach to catchment management that recognised the importance of the river valley and its management in helping the area to respond to the impacts of climate change the threat of flooding, and the pressure for development around the urban fringes of the town. The original stimulus for the GVSP was meeting the requirements of the Water Framework Directive and to develop sustainable approaches to flood risk management. However, from preliminary discussions it was apparent that its remit was changing due to funding and partner support and that it was looking to address wider concerns that included enhancing biodiversity in the area and ensuring that the local environment delivers a range of benefits to local people through education and the economy. The project was therefore selected for EMBED, and the interest here was to understand how and why the initiative broadened in terms of the range of issues considered and what role different sorts of ecosystems knowledge played in this process.

- The Natural Economy Northwest Green Infrastructure Project (NENW): this was a regional partnership programme led by Natural England, the North West Development Agency and the SITA Trust, on behalf of a wide range of economic and environmental partners. It was started in 2007 and ended in 2009, soon after the initiation of EMBED. It was selected as a demonstrator because its greater maturity allowed the influence of some of the project outcomes to be considered as well as using the case study to look only at decision making processes. The focus of NENW was to deliver priority action 113 in the Regional Economic Strategy, namely to optimise the contribution of the natural environment to the regional economy and quality of life. Thus the Project sought to work with a range of regional partners to 'mainstream' the natural environment within sustainable economic development. It therefore differed from the other demonstrator projects in that its main purpose was to influence others rather than to intervene directly, and was of interest from the outset because it allowed the way arguments about the importance of green infra-structure were being made in a number of 'live' initiatives. 
The Wetland Example of Payment for Ecosystem Services Project (WEPES): This was led by the Westcountry Rivers Trust and focussed on water management issues associated with the River Fal in West Cornwall. It started in 2009 and has now been completed. Compared to the other three demonstrators project it was the smallest, focussing on only 21 ha of land. However, it has run in parallel with a larger INTERREG project which had similar objectives - called WATER (Wetted Land: the Assessment, Techniques and Economics of Restoration) which took in the other catchments of the Axe and Exe. Like WEPES, the WATER project has sought to improve the condition of the rivers that discharge into the Channel by developing a 'Payments for Ecosystem Services' (PES) model. The intention is that such scheme will allow farmers and landowners to access funds to achieve long term protection of strategically targeted areas of their land that are important providing ecosystem services. In selecting WEPES for inclusion in EMBED it was felt that the insights would not only be relevant to other river basins, but also more generally for those interested in PES schemes. In the context of EMBED it was felt that the project provided the opportunity to look at the kinds of ecosystem knowledge that are used to advance and implement such schemes, and how such knowledge is martialed and presented in a negotiation process 
Table A1: Overview of EMBED Demonstrator Projects (from Potschin et al., 2011)

\begin{tabular}{|c|c|c|c|c|}
\hline & Finding Sanctuary & Gaywood Valley Surf Project & Natural Economy Northwest (NENW) & $\begin{array}{l}\text { Wetland Example of Payment for } \\
\text { Ecosystem Services }\end{array}$ \\
\hline Overarching project & Marine Conservation Zone Project & $\begin{array}{l}\text { Part of the InterReg SURF project } \\
\text { (SURF = Sustainable Urban } \\
\text { Fringes) }\end{array}$ & Natural Economy North West & $\begin{array}{l}\text { Part of the InterReg IVA WATER project - } \\
\text { Wetted-Land: Assessment, Techniques } \\
\text { and Economics of Restoration. }\end{array}$ \\
\hline Ecosystem Type & Marine and Coast & River basin landscape & Urban \& Rural & Wetland - subcatchment \\
\hline Scale & Regional & Catchment & Local & Site/Catchment \\
\hline Size & $92,000 \mathrm{~km}^{2}$ & 5,700 ha & $\begin{array}{l}8 \text { site-scale redevelopment or regeneration } \\
\text { projects }\end{array}$ & 21 ha \\
\hline Location & $\begin{array}{l}\text { Southwest England (coast and marine } \\
\text { ecosystems of Dorset, Somerset, } \\
\text { Devon, Cornwall and the Isles of Scilly) }\end{array}$ & West Norfolk Borough area & $\begin{array}{l}\text { Northwest England (Warrington, Salford, } \\
\text { Liverpool, Oldham, Rochdale, Blackpool, } \\
\text { Burnley and redevelopment projects in the } \\
\text { Weaver Valley and around Windermere) }\end{array}$ & Southwest England (West Cornwall) \\
\hline Issue & $\begin{array}{l}\text { Defining Marine Conservation Zone } \\
\text { (MCZ) boundaries that will command } \\
\text { support of stakeholders }\end{array}$ & $\begin{array}{l}\text { Making the urban fringe more } \\
\text { accessible and attractive and } \\
\text { introducing multi benefits }\end{array}$ & $\begin{array}{l}\text { Demonstrate cost-effective ways to improve \& } \\
\text { integrate Green Infrastructure (GI) in the } \\
\text { design of projects and by sharing investment } \\
\text { costs amongst beneficiaries. }\end{array}$ & $\begin{array}{l}\text { Using a pilot-scale project to evaluate } \\
\text { the catchment-wide potential of a } \\
\text { 'Payment for Ecosystem Services' } \\
\text { approach in conservation and habitat } \\
\text { restoration efforts. }\end{array}$ \\
\hline Start/end & $9 / 2009$ to $6 / 2011$ & $9 / 2010-8 / 2012$ & $1 / 2007$ to $12 / 2009$ & $3 / 2009$ to $3 / 2011$ \\
\hline Status & $\begin{array}{l}\text { Recommendations made to JNCC and } \\
\text { NE in September } 2011\end{array}$ & Final reports available & $\begin{array}{l}\text { The NENW programme has been completed } \\
\text { and the overall evaluation also done. These } 8 \\
\text { projects are ongoing and ideally monitoring } \\
\text { outcomes would be desirable. The work is now } \\
\text { being progressed by such initiatives as Green } \\
\text { Infrastructure Valuation Network and Green } \\
\text { Infrastructure to Combat Climate Change }\end{array}$ & $\begin{array}{l}\text { Autumn 2011, but major outcomes } \\
\text { including an assessment of the payment } \\
\text { for ecosystem services model due by } \\
\text { summer } 2011\end{array}$ \\
\hline Overall budget & Approx. $\mathrm{f} 1$ million & $£ 500,000$ plus ca. $€ 32.000$ & $\begin{array}{l}\text { Total NENW budget } £ 3 \text { million - These } 8 \\
\text { projects formed part of the NENW programme. }\end{array}$ & Approx. $£ 90,000$ \\
\hline Funding source & $\begin{array}{l}\text { Past: Esmée Fairbairn Foundation, } \\
\text { Defra Challenge Fund, Oak Foundation, } \\
\text { FIFG, South West RDA, Cornwall County } \\
\text { Council, National Trust, Devon County } \\
\text { Council, RSPB. Currently funded by } \\
\text { Natural England and Interreg. }\end{array}$ & $\begin{array}{l}\text { Interreg North Sea Project } \\
\text { (Europe) } \\
\text { Some match funding by Norfolk } \\
\text { County Council and West Norfolk } \\
\text { Borough Council }\end{array}$ & $\begin{array}{l}\text { Natural England, the Northwest regional } \\
\text { Development Agency, the SITA Trust }\end{array}$ & $\begin{array}{l}\text { Natural England, DEFRA, EU Interreg } \\
\text { Manchester, Springboard, RELU. }\end{array}$ \\
\hline Websites & www.finding-sanctuary.org & $\underline{\text { www.sustainablefringes.eu }}$ & www.naturaleconomy northwest.co.uk & $\begin{array}{l}\text { http://www.wrt.org.uk/ } \\
\text { and } \\
\text { http://www.wrt.org.uk/projects/wepes/ } \\
\text { wepes.html }\end{array}$ \\
\hline
\end{tabular}


